Louisiana State University

LSU Digital Commons

Faculty Publications

School of Electrical Engineering \& Computer

Science

$10-2020$

\title{
Secure High DER Penetration Power Distribution via Autonomously Coordinated Volt/VAR Control
}

\author{
Anto Joseph \\ Univ Calif Irvine, Dept Elect Engn \& Comp Sci, Irvine, CA 92697 USA, ajosephr@uci.edu \\ Keyue Smedley \\ Univ Calif Irvine, Dept Elect Engn \& Comp Sci, Irvine, CA 92697 USA, smedley@uci.edu \\ Shahab Mehraeen \\ Louisiana State Univ, Elect \& Comp Engn Dept, Baton Rouge, LA 70803 USA, smehraeen@lsu.edu
}

Follow this and additional works at: https://digitalcommons.Isu.edu/eecs_pubs

Part of the Electrical and Computer Engineering Commons

\section{Recommended Citation \\ Joseph, A., Smedley, K., \& Mehraeen, S. (2020). Secure High DER Penetration Power Distribution via Autonomously Coordinated Volt/VAR Control. IEEE TRANSACTIONS ON POWER DELIVERY, 35 (5), 2272-2284. https://doi.org/10.1109/TPWRD.2020.2965107}

This Article is brought to you for free and open access by the School of Electrical Engineering \& Computer Science at LSU Digital Commons. It has been accepted for inclusion in Faculty Publications by an authorized administrator of LSU Digital Commons. For more information, please contact ir@lsu.edu. 


\section{UC Office of the President}

Recent Work

\section{Title}

Secure High DER Penetration Power Distribution Via Autonomously Coordinated Volt/VAR Control

\section{Permalink}

https://escholarship.org/uc/item/17k4847d

\section{Authors}

Joseph, Anto

Smedley, Keyeu

Mehraeen, Shahab

\section{Publication Date}

2020

Peer reviewed 


\title{
Secure High DER Penetration Power Distribution Via Autonomously Coordinated Volt/VAR Control
}

\author{
Anto Joseph, Keyue Smedley, Fellow, IEEE, and Shahab Mehraeen, Member, IEEE
}

\begin{abstract}
Traditionally voltage control in distribution power system (DPS) is performed through voltage regulating devices (VRDs) including on load tap changers (OLTCs), step voltage regulators (SVRs), and switched capacitor banks (SCBs). The recent IEEE 1547-2018 from March 2018 requires inverter fed distributed energy resources (DERs) to contribute reactive power to support the grid voltage. To accommodate VAR from DERs, well-organized control algorithm is required to use in this mode to avoid grid oscillations and unintended switching operations of VRDs. This paper presents two voltage control strategies (i) static voltage control considering voltage-reactive power mode (IEEE 1547-2018), (ii) dynamic and extensive voltage control with maximum utilization of DER capacity and system stability. Further, effective time-graded control is implemented between VRDs and DER units to reduce the simultaneous and negative operation. The proposed voltage control strategies are tested in a realistic 140-bus southern California distribution power system through extensive time-domain simulation studies. The results show that voltage quality in a distribution system is effectively achieved through the proposed voltage control strategies with a significantly reduction in the number of switching operations of VRDs. In addition, proposed voltage control strategies increase reliability and security of the DPS during unexpected failures.
\end{abstract}

Index Terms-distribution system voltage control, voltage regulating devices, distributed energy resources, reactive power control.

\section{INTRODUCTION}

$\mathrm{D}$ ISTRIBUTION power system plays an important role in the electrical power system as a mean to deliver power to the customers. The penetration of distributed energy resources such as wind and solar photovoltaic (PV) generation has been steadily increasing from $238 \mathrm{GW}$ in the year 2010 to $941 \mathrm{GW}$ in 2017 , and the trend is continuing, through advanced energy and control technologies, with improved efficiency, reliability of power and $\mathrm{CO}_{2}$ reduction [1], [2]. Regardless of their benefits, DERs can cause voltage instability in DPS due to their intermittent power generation [3]. Conventionally, distribution system voltage is regulated through OLTCs, SVRs and SCB/SIBs, etc. However, operation of these units is challenged by DER-rich distribution systems in view of

This work is supported by the University of California, Office of the President under Grant No. LFR-18-548175.

A. Joseph and K. Smedley are with the Department of Electrical Engineering and Computer Science, University of California, Irvine, CA, USA. (ajosephr@uci.edu, smedley@uci.edu)

S. Mehraeen is with the Electrical and Computer Engineering Department, Louisiana State University, Louisiana, USA. (e-mail: smehraeen@1su.edu) various issues by increased working frequency that impacts cost as they get ware out much quickly. Therefore, grid operators are demanding voltage support from smart inverter fed DER units via reactive power control, which has been advised by IEEE 1547-2018 from March 2018[4].

Over the years, considerable research has been conducted in the area of reactive power control of DER units with respect to the modes of operation including (i) constant power factor mode, (ii) voltage-reactive power mode, (iii) active powerreactive power mode, and (iv) constant reactive power mode [4], [5]. The various autonomous voltage control strategies for the inverters applied to DER units are detailed in [6]. The control strategies are analyzed in the various real distribution systems in United States using OpenDSS. It shows that volt/VAr control is most effective and regulate the voltage caused by DER generations. However, it does not detail the response time for the reactive power support from inverter unit. The study in [7] proposed the non-linear reactive power control in DER units for increasing the penetration of DER units in DPS. It has calculated the required reactive power from DER active power generation and impedance of the line. The authors of [8] tested the voltage support to the grid through an automated predetermined active and reactive power support function from a battery energy storage system, beyond the standards It has showed that the proposed strategy has achieved grid stability with power balancing in high penetration PV/wind. The study in [9] proposed the voltage droop based autonomous reactive power control, it provides reactive power support to the grid based on change in grid voltage. $X$. Zhao et al reviewed the various functions used in the modern smart inverter unit and discussed the reactive power control strategies for the reliable operation of high DER penetrated power system [10]. Even though, various studies have been done regarding autonomous reactive power control in DER units, still several researches are required including: (i) response time for DER-reactive power support to the grid, since it is essential in practical applications in view of stability of the grid and protection devices employed in the system, (ii) maximizing the reactive power support to the grid considering safety voltage region of the distribution system.

Several studies have addressed the grid voltage support in coordination with VRDs including OLTC, SVR, SCB, static VAR compensator (SVC), static synchronous compensator (STATCOM), dynamic VAR compensator (DVC) and DER units [11]-[18]. In addition, utilities employed these devices in their distribution system to improve the voltage stability, 


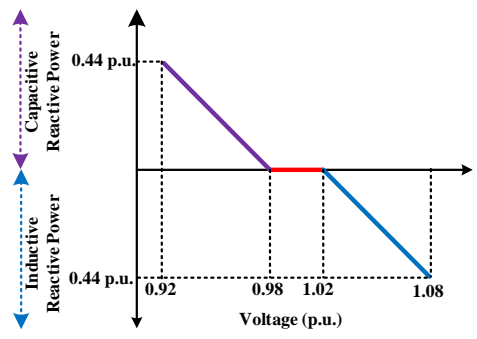

(a) voltage-reactive power mode

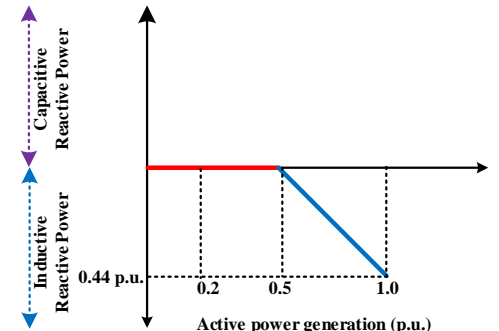

(b) active power - reactive power mode

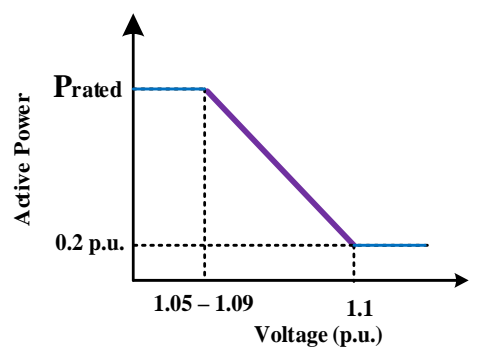

(c) voltage-active power mode

Fig. 1 Grid voltage support through reactive and active power control of DER units per IEEE 1547-2018

VRDs can be employed either individually or in coordinated operation. Article [11] reported that DER units can be effectively utilized to support the grid voltage within their capacity limit. The study in [12] investigated the interaction of synchronous machine fed distribution generation units and voltage regulators in a realistic medium voltage feeder. Authors of [13] analyzed the voltage control issues in distribution system with OLTC, SCB and DER units. The study in [14] has detailed the parallel operation of an autonomous OLTC control and autonomous solar PV reactive power control for controlling grid voltage in the PV-rich DPS in Germany. It investigated the unintended OLTC switching operations with different reactive power control strategies in PV and concludes that voltage-reactive power mode showed a less impact on the number of unintended OLTC switching operations. Study [15] shows that the coordinated operation of remote monitoring based OLTC control and autonomous PV reactive power control in Taiwan power grid mitigates the impacts of voltage quality due to the high PV penetration in the system. Reference [16] investigated the online voltage control strategy for an Australian grid containing voltage regulating devices and DER units. The combined autonomous (local) and centralized voltage control through the reactive power control of DER units is discussed in [17]. It has showed that local control of DER unit follows the IEEE 1547-2018 guidelines and if the reactive power is further available (estimated based on apparent power limit) then it is instructed by centralized control system to provide the available reactive power support. It is observed that the autonomous and remote control of DER units requires to support the grid takes minimum 3s-90s after the voltage variations, restricted by the IEEE guidelines in view of grid oscillatory behavior, and protection devices. In summary, present literatures generally focus on the control of VRDs and DER units through online/remote communication control for the better grid operation. In addition, several studies have suggested to incorporate the additional voltage regulators such as SVC, STATCOM and DVC units in the DER-rich distribution systems to regulate the grid voltage. Further, utilities have followed the IEEE 1547-2018 regulations in their DER units. Nevertheless, in view of cost and placement of voltage regulating devices, the utilities are requiring: (i) autonomous or minimum communication and time-graded operation of VRDs and DER units, (ii) maintain the grid voltage quality without adding the further voltage regulators such as SVC, STATCOM, DVC, etc.

This paper aims to secure the high DER penetration power distribution through the coordinated operation of voltage regulating devices and DER units by investigating the performance of the devices in a practical situation. The main contribution of this paper includes (i) extensive utilization of DER reactive power without affecting active power generation; which reduces the number of switching operation of OLTC, SVRs and improves the voltage quality without additional STATCOM, DVC units (ii) reduction of the grid voltage oscillations and system losses, (iii) it has discussed the response time of DER- reactive power support to the grid considering voltage stability and protection devices employed in the system, (iv) time-graded operation among the VRDs and DER units, which improves the reliability and avoids extra expenses in view of measurement and communication infrastructure, (v) dynamic and maximum grid voltage support during disturbances including active power and load fluctuations, (vi) maintain the voltage quality during unexpected natural, physical and cyber-attacks on the distribution power system.

\section{A. Problem Description and Importance of Work}

The increased penetration of DERs in distribution power systems imposes challenges to the grid operators in view of maintaining voltage security, voltage stability and grid flexibility of the system. It is required that system should able to maintain the voltage within the safety margin (i.e. voltage security) during the disturbances; if any voltage violation occurs then the system is not able to meet increased demand for active and/or reactive power and lead to shutdown of a total (or significant part) power distribution system. In addition, transient and steady state voltage stability of a high DER penetrated power distribution is a major concern due to the increased physical and cyber-security threads on smart meters and smart inverter units.

The recent change in IEEE 1547-2018 calls participation of DER units to support the grid voltage. Commonly, voltagereactive power mode is preferred among the grid operators to provide the reactive power support to the grid. In this mode, each DER unit can support reactive power to the grid with respect to the maximum of $44 \%$ of their capacity and it follows the curve as shown in Fig.1a and eqn (1).

By following the voltage-reactive power curve (IEEE 15472018), it is noted that light penetration (e.g. less than 20\%) of the DERs in the distribution system has less impact on supporting the grid voltage due to the minimum reactive power support. In case of high DERs penetration (e.g. more than $75 \%$ ), the same support could produce grid oscillatory behavior and generate voltage transients in the system. This paper follows the method to support the reactive power to the grid based on the DERs penetration in the distribution system. The reactive power support is limited through active power 
generation and apparent power of the DER units. Also, reactive power support is following the non-linear sensitivity matrix (i.e. change in voltage $\mathrm{Vs}$ change in reactive power curve) of a certain distribution system. This paper proposes a hysteresis based wide bandwidth control in DER units to support the reactive power to the grid which reduces the high computational and hard process tuning of the controllers; also reduce the grid oscillatory actions. In addition, with the delay time of the OLTC, SVR, SCB, DER-reactive power support set properly, autonomous coordination can be achieved.

The proposed method can provide benefit to the utilities in view of maintaining the voltage quality without adding the further voltage regulating devices and reduce the mechanical maintenance of OLTC and SVRs. In addition, the research findings from this paper shall be useful for the grid operators and policy makers for the safe operation of the DPS.

\section{B. Organization of the Paper}

Section II discusses the control strategy, operation and practical limitations of conventional voltage regulating devices and DER units. The proposed grid voltage control strategies are discussed in section III. To understand the effect of the proposed voltage control strategies, a realistic 140-bus southern California distribution power system is simulated in Matlab/Simulink and the results are discussed in section IV. Concluding remarks are summarized in section $\mathrm{V}$.

\section{VOLTAGE CONTROL AND OPERATION OF VRDS AND DERS}

\section{A. DER Unit}

Smart inverter fed DER unit is considered as a grid voltage regulator, which supplies both inductive and capacitive reactive power by controlling the phase angle of the ac current relative to the ac voltage. As per IEEE1547-2018, DER unit can supply the reactive power of $44 \%$ of the unit capacity with the constrains of minimum $20 \%$ active power generation required, whereas $10 \%$ active power generation in the unit can support $22 \%$ reactive power to the grid as framed by (1) which is applicable during less than $20 \%$ active power generation

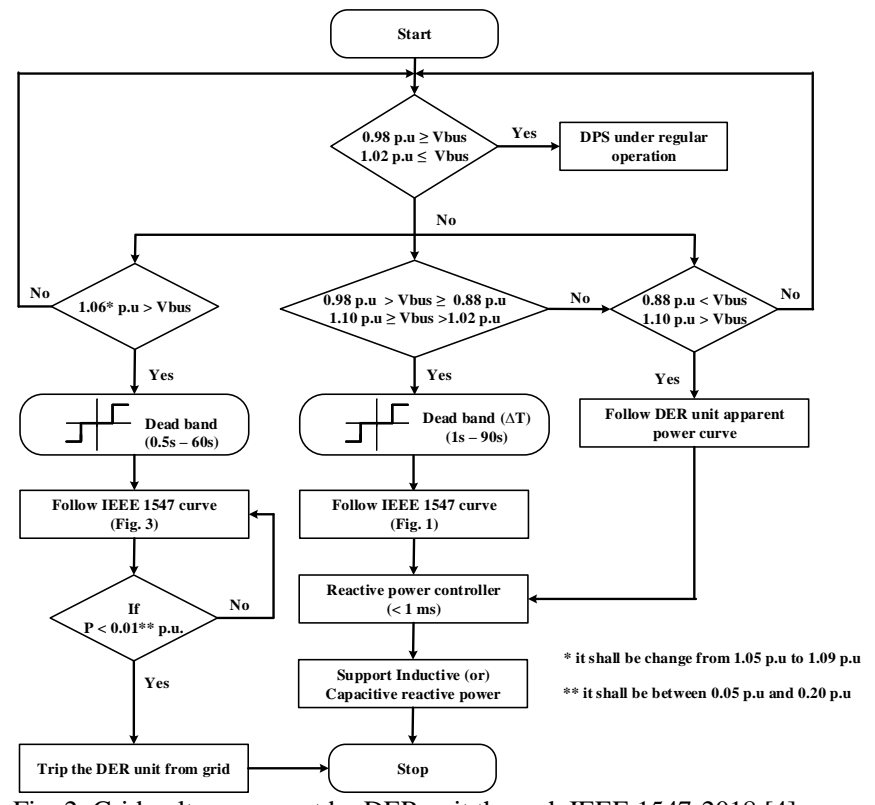

Fig. 2. Grid voltage support by DER unit through IEEE 1547-2018 [4]

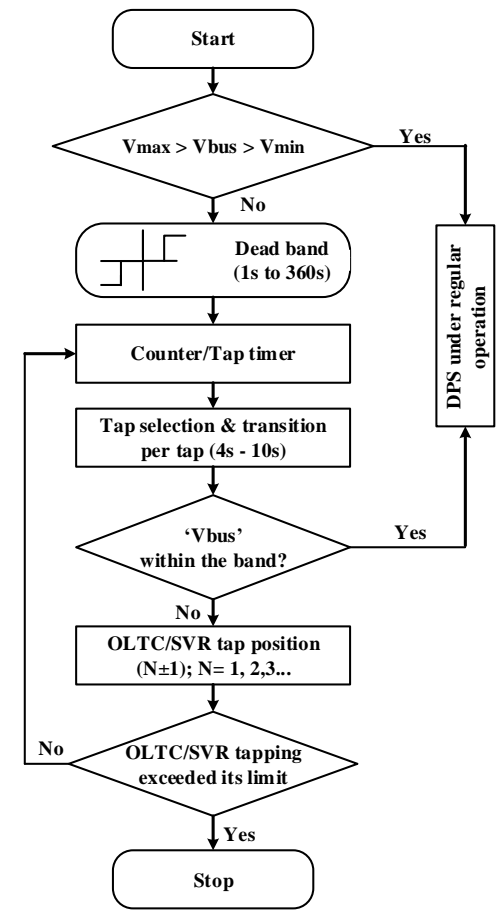

Fig. 3. Grid voltage support through OLTC/ SVR unit

[4].

$$
Q_{g}=-\frac{0.44 \text { p.u. } \times \text { active power generation }}{0.2 \text { p.u. }}
$$

Figure 1a, and Figure 1b shows the voltage and active power based reactive power control strategies of DER units, respectively. Further, constant power factor mode and constant reactive power mode control strategies are applicable to the DER units. Based on these control strategies, during operational voltage region $(<0.88 \mathrm{p}$. u to $1.10 \mathrm{p}$. u) that DER unit can provide maximum of $44 \%$ reactive power support to the grid between $1 \mathrm{~s}$ and $90 \mathrm{~s}$ to maintain the grid voltage. However, less than $3 \mathrm{~s}$ is not usually permitted by the local grid operators to avoid oscillatory actions. The reactive power capability of DER unit can be utilized to the greatest possible extent during the abnormal voltage range $(<0.88 \mathrm{p}$. $\mathrm{u}$ or $>1.10$ p.u) and it should be reverted within $5 \mathrm{~s}$ after the fault clearance. In addition, curtailment of active power generation is required based on voltage-active power control mode (shown in Fig.1c) to regulate the grid voltage through DERsmart inverter controller. A flowchart indicating the grid voltage support through DER unit is shown in Fig. 2 It is noted that DER unit can be disconnected from the grid if the active power generation is less than 0.05 p.u. during faulty conditions. Nevertheless, DER units must follow the fault-ride through procedure discussed in ref [4]. The DERs reactive power can be controlled through autonomous (local) control system or it can be remotely controlled by grid operators through centralized control. Remote control provides precise voltage control in the system; however, it requires communication and measurement complexities. Further, the remote-controlled system could be much concern in view of cybersecurity issues.

The influencing factors for the time delay in reactive power controller at DER units are discussed below,

$i$. dynamics of synchronous generators 
Table 1. Time delays corresponding to DER and VRD units

\begin{tabular}{|c|c|c|c|c|c|c|c|c|c|c|}
\hline \multirow[b]{2}{*}{$\begin{array}{c}* \text { Synchronous } \\
\text { generator } \\
\text { dynamics }\left(\tau_{\mathrm{s}}\right)\end{array}$} & \multirow{2}{*}{$\begin{array}{c}\text { DER Unit } \\
\text { Time delays } \\
* * \text { Transient } \\
\text { current decay } \\
\left(\tau_{\mathrm{t}}\right)\end{array}$} & \multirow[b]{2}{*}{$\begin{array}{c}* * * \text { Auxiliary } \\
\text { time constant } \\
\left(\tau_{\mathrm{a}}\right)\end{array}$} & \multicolumn{3}{|c|}{ SCB Time delays [21], [22] } & \multicolumn{2}{|c|}{$\begin{array}{c}\text { SVR/OLTC } \\
\text { Time delays [23], [24] }\end{array}$} & \multicolumn{3}{|c|}{$\begin{array}{c}\text { DER - VRDs } \\
\text { Coordination Time delays }\end{array}$} \\
\hline & & & $\begin{array}{l}\text { Intentional } \\
\text { time delay }\end{array}$ & $\begin{array}{l}\text { Operational } \\
\text { time delay }\end{array}$ & $\begin{array}{c}\text { Mandatory } \\
\text { discharging } \\
\text { time }\end{array}$ & $\begin{array}{l}\text { Intentional } \\
\text { time delay }\end{array}$ & $\begin{array}{l}\text { Operational } \\
\text { time delay }\end{array}$ & $\begin{array}{c}* * * * \text { Grid } \\
\text { measurements } \\
\text { time constant } \\
\left(\tau_{\mathrm{m}}\right)\end{array}$ & $\begin{array}{c}\text { Proposec } \\
\text { Static } \\
\text { voltage } \\
\text { control } \\
\end{array}$ & $\begin{array}{c}\text { control strategy } \\
\text { Dynamic and } \\
\text { extensive } \\
\text { voltage control }\end{array}$ \\
\hline$\sim 1 \mathrm{~s}$ & $\sim 1 \mathrm{~s}-5 \mathrm{~s}$ & $\sim 2 \mathrm{~s}$ & $1 s-60 s$ & $0 s-10 s$ & $60 s-360 s$ & $30 s-360 s$ & $4 s-10 s$ & $\sim 2 s-5 s$ & $\tau_{\mathrm{s}}+\tau_{\mathrm{t}+} \tau_{\mathrm{m}}$ & $\tau_{\mathrm{s}}+\tau_{\mathrm{t}}+\tau_{\mathrm{a}+} \tau_{\mathrm{m}}$ \\
\hline
\end{tabular}

Typically, grid protection devices and fault-spot-detection algorithms are following the dynamics of synchronous generator (SG) where the excitor time constant is about $1 \mathrm{~s}$ as defined by damper and excitation windings [19]. The grid-tied converter does not have such windings in the structure, and it supports reactive power to the grid through power converter and its control system. Presently, in order to mimic the synchronous generator dynamics, a time constant (equal to the SG-excitor time constant) is selected for the reactive power controller in the grid-tied converter for the suitable operation of conventional protection devices.

\section{ii. stability of the distribution power system}

Stability of the grid is determined by several factors and one of the most promising influence is rate of change of reactive power support during disturbances. Fast response of the reactive power controller diminishes first cycle transients; however, it increases the grid oscillatory actions in the subsequent cycles due to the closed positive feedback loop [20]. Therefore, a time constant is selected in consideration of transient current decay which is determined by the resistance and reactance of a certain distribution system. This time constant is estimated by dividing the reactance to resistance in the distribution system.

\section{B. Switched Capacitor/Inductor Bank}

Switched capacitor bank can provide capacitive reactive power to the grid; likewise, inductor bank can provide inductive reactive power. Like reactive power control in DER units, switching of SCB can be operated through either manual or autonomous modes (voltage or time based). In both modes, repeated switching is limited due to the electrical trapped charges within the capacitor units. Therefore, minimum discharging time is mandated, and it could be 60 s to 360 s for the distribution system capacitor banks [21], [22]. In case of voltage based autonomous mode, dead band and counter setting are designed such that $\mathrm{SCB} / \mathrm{SIB}$ is not switched during the voltage transients or less voltage dips. In addition, intentional time delay (0s to 60s) is planned in consideration of other voltage regulating devices like OLTC, DER units, etc. Further, operational time delay (i.e. counter setting/dead band) is set at $0 \mathrm{~s}$ to $10 \mathrm{~s}$. These banks are connected to the grid through vacuum circuit breaker that produces voltage transients during switching. Therefore, capacitor banks are typically controlled manually or via time-based autonomous control in DPS to reduce the number of switchings, mechanical maintenance, and interaction among the other VRDs, and DER units.

\section{On Load Tap Changer and Step Voltage Regulator}

On load tap changers and step voltage regulators are used to regulate the grid voltage during voltage dip/voltage sag. Generally, OLTC is connected near the substation to regulate the voltage, whereas SVRs are connected downstream of the distribution feeders. Similar to voltage based autonomous SCB control unit, dead band, counter setting and intentional time delay is designed in OLTC/SVR control unit to reduce unintended operations. The operational time delay in SVR units are typically set as minimum compared to OLTC unit. The tap selection and tap transition units are employed in both units and (i.e. motor drive mechanism) requires $5 \mathrm{~s}$ to $10 \mathrm{~s}$ to make one tap change operation [23], [24]. Further, intentional time delay can be varied from 1s to 360 s to avoid tap changing operation during transients and is, commonly set at about $30 \mathrm{~s}$ $60 \mathrm{~s}$ by grid operators. Further, voltage dead band is selected based on the location of the unit and loads. The tap timer is controlled through reset logic includes and (i) instantaneous reset, (ii) integrating reset, (iii) delay reset, and (iv) delay freeze reset. In addition, line drop compensation (LDC) algorithm is implemented to estimate the voltage drop at the end of the distribution circuit. The typical control logic employed in the OLTC/SVR unit is shown in Fig. 3 [23]. Table.1 indicates different time delay ranges for different mechanisms that are used to achieve coordination and stability of the entire control system.

Based on the practical limitations, instantaneous voltage support to the grid is not feasible through OLTC, SVR, or SCBs. In case of DER units, dynamic and full range of reactive power support is not permitted in the voltage region between $0.88 \mathrm{p}$. u and $1.1 \mathrm{p}$. u through IEEE guidelines. It can provide the static and minimum reactive power support (i.e. reactive power support is limited by $44 \%$ of the unit capacity, and it can respond after $3 \mathrm{~s}-5 \mathrm{~s}$ from the voltage variation) to the DPS during the aforesaid voltage region. However, voltage supplied at the distribution system, as defined by ANSI C 84.1 is between 0.95 p. u and 1.05 p. u [25].

\section{Proposed Grid Voltage Control Strategies}

Two voltage control strategies are proposed in DER units to ensure voltage quality in DPS and reduce the number of VRD switching operations. Furthermore, time-graded control is employed in between SCB, OLTC, SVR and DER units for the increased utilization of DER units.

\section{A. Static Voltage Control Strategy}

The proposed static voltage control aims to reduce grid oscillations as compared to the conventional IEEE1547-2018 method. This strategy controls the voltage in DPS based on IEEE voltage-reactive power curve; and reactive power response time $(1 \mathrm{~s}-90 \mathrm{~s})$ is selected in view of practical 


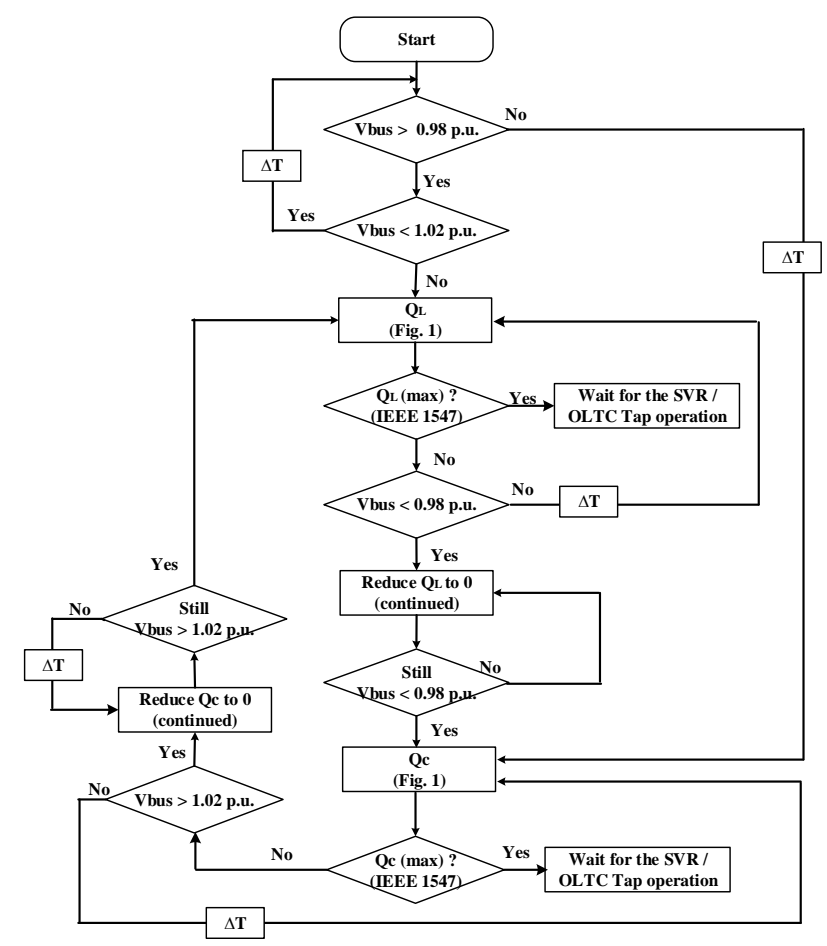

Fig. 4. Proposed static voltage control method

constrains such as synchronous generator dynamics and transient current decay of a DPS. Grid voltage-oriented vector control system or one cycle control can be employed in smart inverter to control the active and reactive power delivery of the DER units. However, supplying inductive or capacitive reactive power from the DER units follows the hysteresis based wide bandwidth control strategy proposed in Fig. 4. In this proposed strategy, provision of inductive reactive power is returned when bus voltage is reduced to $0.98 \mathrm{p}$. u, instead of 1.02 p. $\mathrm{u}$ as followed in IEEE 1547-2018. Likewise, capacitive reactive power is returned at 1.02 p.u. instead of 0.98 p.u., subsequently, it reduces the grid oscillatory actions since it minimizes the number of DERs switching operations through the operated bandwidth. A suitable time-delay is maintained between DER and VRD units for maximizing the voltage support from DER units and avoid unintended switching operations of VRDs. It depends on DER-reactive power controller time constant and distance (i.e. impedance) between
DER and VRD units. If more SVR units are connected in the system, then the minimum time delay from one SVR unit to the next one is $15 \mathrm{~s}$ and it is continually added [26]. In case more SCBs are connected in the system, then all the SCBs are operated through time-based autonomous control based on projected load profile as discussed in this paper. If the SCBs are to be connected through voltage-based autonomous control, then preference will be given to SCBs than SVR units by setting suitable time-delays considering DER-reactive power switching. The reference voltages for the VRD and DER units are taken from their locations; therefore, remote communication and measurement infrastructure are avoided. The proposed control strategy reduces the number of VRD switching operations compared to the conventional voltage control method (i.e. IEEE 1547-2003/2013). Also, it can reduce the grid oscillations compared to IEEE 1547-2018. This control strategy can be applied to the currently employed DER units in the utilities without violating IEEE 1547-2018 regulations.

\section{B. Dynamic and Extensive Voltage Control Strategy}

The dynamic and extensive voltage control strategy in DER units provide reactive power support to the grid based on DER unit capacity and active power generation. It provides dynamic voltage support to the grid during DER active power variations and reduces the number of VRD switching operations compared to the proposed static voltage control, and IEEE 1547:2018 strategies. Further, it increases the reliability of DPS during unexpected failures though the extensive utilization of DER-reactive power support. The proposed voltage control strategy comprises of: (i) dynamic reactive power control (RPC) block, (ii) static RPC stage-I, and (ii) static RPC stage-II blocks. The dynamic RPC injects instantaneous reactive power support to the grid during active power variations in DER units. Possibility of dynamic reactive power support is presented in subsequent subsection. Static RPC stage-I is similar to the proposed static voltage control strategy, it follows the IEEE voltage-reactive power characteristics and provides grid support during unexpected changes in loads and short time faults. If the support is continually required and the grid voltage is away (e.g. $<0.95$

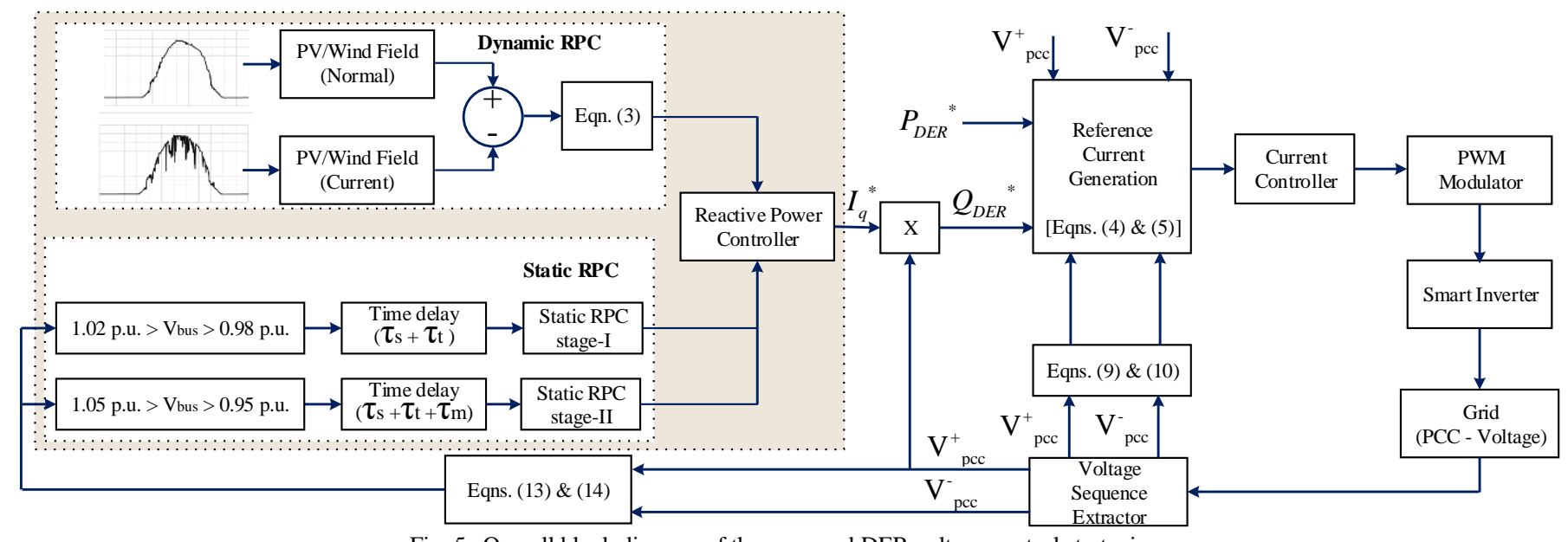

Fig. 5a Overall block diagram of the proposed DER voltage control strategies 
p. u or $>1.05$ p. u) from the stipulated bandwidth then control is switched into the static RPC stage-II mode. In this mode DER unit provides maximum available reactive power to the grid in view of DER unit capacity and active power generation. This control strategy can provide both voltage stability and grid flexibility to the DPS. The transient voltage stability and grid flexibility is attained through dynamic RPC block and steady state voltage stability is achieved by static RPC stage-I and stage-II blocks. This control strategy might violate the current IEEE 1547-2018 regulations in view of maximum usage of reactive power support, however utilities can get more benefits by this control strategy including voltage quality improvement and reduction in number of switching operations of OLTC and SVR units.

The coordination between dynamic RPC, static RPC stage-I and static RPC stage-II is implemented based on time delays and grid voltage as shown in Fig. 5a. It is inferred that that

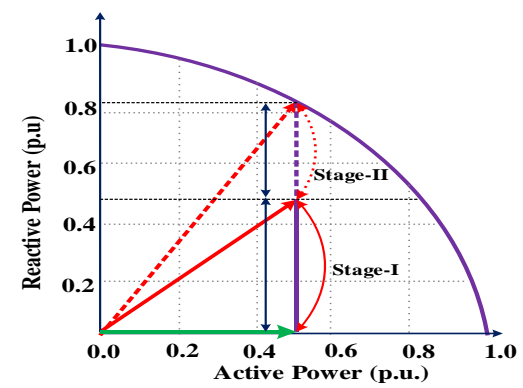

Fig. 5b. Extensive Reactive power support with active power of 0.5 p. u dynamic RPC is neither employed with time delay nor controlled by grid voltage, but it instantaneously supports reactive power to the grid whenever DER active power variation is occurred through droop control technique. The active power variation is estimated by comparing the normal (projected through weather forecasting) and current active power generation. The static RPC stage-I provides reactive power support to the grid when the grid voltage goes either greater than 1.02 p.u. or less than 0.98 p.u. (based on IEEE $1547 \mathrm{std})$. In addition, it follows the time delay considered by synchronous generator and transient current decay time constants. In case of static stage-II, it is enabled after the static RPC stage-I by adding the required time delay considering grid measurements. In addition, it triggers when the grid voltage goes either greater than 1.05 p.u. or less than 0.95 p.u. as it is considered as a safety voltage margin of the system. The stage-II reactive power support follows the nonlinear Q-V curve presented in [27], which can be more efficient and accurate in view of stability of the system.

(i) Possibility of dynamic reactive power support from DERs

Conventionally, dynamic reactive power support from DER units is restricted in view of time constants related to synchronous generator dynamics and transient current decay. In highly DER-penetrated distribution system, voltage transients are mostly due to the sudden change in DER active power generation (e.g. cloudy transients in solar PV). If one can mitigate voltage transients due to the DER units then it

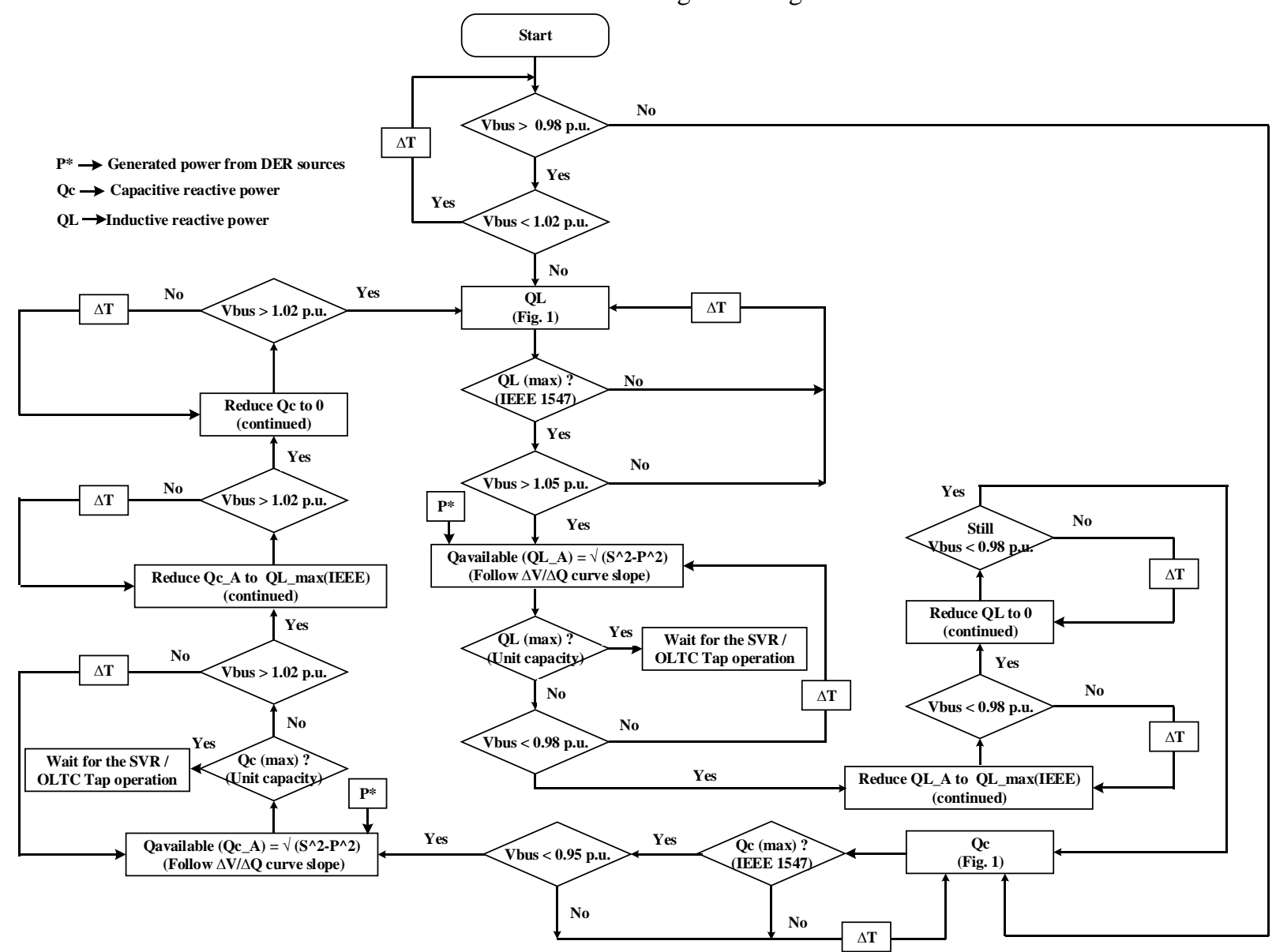

Fig. 5c. Control diagram of proposed dynamic and extensive voltage control strategy 
can certainly increase voltage quality and grid flexibility of the system. It is noted that synchronous generator dynamics is similar for the normal and abnormal generation in DER units. Therefore, if one can dynamically mitigate voltage transients due to the active power variation then it cannot be affecting synchronous generator dynamics. Similarly, transient current decay is not a concern by injecting dynamic reactive power during the active power variation in DER units since reactive power is not controlled by closed feedback loop. Equation (2) shows the change in voltage at point of common coupling (PCC) of the DER unit as a function of active $(\mathrm{P})$ and reactive power (Q) delivery [28]

$$
\Delta V_{P C C} \approx \frac{\Delta P_{D E R} \times R+\Delta Q_{D E R} \times X}{V_{P C C}}
$$

where

$\Delta \mathrm{V}_{\mathrm{PCC}} \rightarrow$ change in voltage at $\mathrm{PCC}$

$\Delta \mathrm{P}_{\mathrm{DER}} \rightarrow$ change in active power generation in the DER unit

$\Delta \mathrm{Q}_{\mathrm{DER}} \rightarrow$ change in reactive power delivery in the DER unit

$\mathrm{R} \rightarrow$ resistance between DER connected bus and main station

$\mathrm{X} \rightarrow$ reactance between DER connected bus and main station

The voltage variation at PCC can be mitigated by supplying required reactive power from DER unit and it is based on,

$$
\Delta Q_{D E R} \approx-\Delta P_{D E R} \times\left(\frac{R}{X}\right)
$$

The active power variation of a DER unit can be obtained by comparing current active power generation and normal day generations. The $\mathrm{R} / \mathrm{X}$ value is constant, it depends on line parameters (i.e. Thevenin equivalent impedance of the bus from the main power station) and is not load dependent. Although, resistance of the line is temperature dependent which changes during loading, it is considered as negligible. If one can dynamically calculates active power variation, then dynamic reactive power support is achievable during the active power variation in DER units. In addition, this dynamic reactive power support can be utilized to mitigate the capacitor switching transients through suitable control system.

(ii) Reactive power support during unbalanced grid voltage

The amount of negative sequence voltage present at the PCC with respect to positive sequence is called as voltage unbalanced factor. The unbalanced current generation algorithm is employed as a portion of the proposed voltage control strategies for handling the unbalanced voltage conditions. Also, reactive power support from DER unit is estimated based on positive and negative sequence voltage leads to reduce the imbalance in the grid voltage.

It is well known that controlling DER positive and negative sequence output current could compensate the PCC unbalanced voltage. According to the instantaneous power theory, positive and negative sequence of the DER output current reference is calculated by [29],

$$
I_{D E R}{ }^{+*}=\left(\frac{k_{1} P_{D E R}{ }^{*}-j k_{2} Q_{D E R}{ }^{*}}{\left|V^{+}{ }_{p c c}\right|^{2}}\right) V_{p c c}^{+}
$$

$I_{D E R}^{-*}=\left(\frac{\left(1-k_{1}\right) P_{D E R}^{*}+j\left(1-k_{2}\right) Q_{D E R}^{*}}{\left|V_{p c c}^{-}\right|^{2}}\right) V_{p c c}^{-}$

where

$P_{D E R}{ }^{*} \rightarrow$ average active power reference.

$Q_{D E R}{ }^{*} \rightarrow$ average reactive power reference.

$V_{p c c}^{+} \rightarrow$ positive sequence voltage at PCC

$V_{p c c}^{-} \rightarrow$ negative sequence voltage at PCC

$k_{1}=\frac{\text { positive sequence activepower }}{\text { Total active power }}$

$k_{2}=\frac{\text { positive sequence reactivepower }}{\text { Total reactive power }}$

During unbalanced condition, total DER active power to the grid is,

$$
P=\left(V_{p c c}^{+}+V_{p c c}^{-}\right) \times\left(I_{D E R}^{+*}+I_{D E R}^{-*}\right)
$$

From (6), the oscillated active power is calculated as

$$
\tilde{\boldsymbol{P}}=\left(V_{p c c}^{+} \times I_{D E R}^{-*}\right)+\left(V_{p c c}^{-} \times I_{D E R}^{+*}\right)
$$

It is desired to obtain zero active power oscillation that is essential during unbalanced voltage condition, therefore (7) is modified into,

$\left(V_{p c c}^{+} \times I_{D E R}^{-*}\right)+\left(V_{p c c}^{-} \times I_{D E R}^{+^{*}}\right)=0$

Substitute $I_{D E R}^{{ }^{+*}}$ and $I_{D E R}{ }^{-*}$ in (8) then calculate the factors $\mathrm{k}_{1}$ and $\mathrm{k}_{2}$,

$$
\begin{aligned}
& k_{1}=\frac{1}{1-\left(\left|V_{p c c}^{-}\right|^{2} /\left|V_{p c c}^{+}\right|^{2}\right)} \\
& k_{2}=\frac{1}{1+\left(\left|V_{p c c}^{-}\right|^{2} /\left|V_{p c c}^{+}\right|^{2}\right)}
\end{aligned}
$$

The average active and reactive power reference are calculated with help of dc link voltage controller (active power controller) and proposed reactive power controller in the DER unit, respectively. It is given below.

$$
\begin{aligned}
& P_{D E R}{ }^{*}=\left|I_{d}{ }^{*}\right| \times\left|V^{+}{ }_{p c c}\right| \\
& Q_{D E R}{ }^{*}=\left|I_{q}{ }^{*}\right| \times\left|V^{+}{ }_{p c c}\right|
\end{aligned}
$$

The PCC positive and negative sequence voltage are calculated with the help of three phase PLL system and corresponding current reference are generated by (4) and (5). These current references are further processed with inner current controllers and generates gate signals for the smart inverter through PWM modulators.

The input voltage to the proposed reactive power control is obtained based on positive and negative sequence voltages, which further minimize the imbalance in the grid voltages.

$V_{\text {control_reactivepower }}=k^{+} \times V_{p c c}^{+}+k^{-} \times V_{p c c}^{-}$

$k^{-}=1-k^{+}, k^{+}$varies from 0 to 1 .

Where $k^{+}$and $k^{-}$are the normalized factors to balance between the positive and negative sequence voltages. The proper selection of these factors helps to increase the voltage balance among the phase voltages. The selection of $k^{+}$value is based on the practical constrains is given below. 


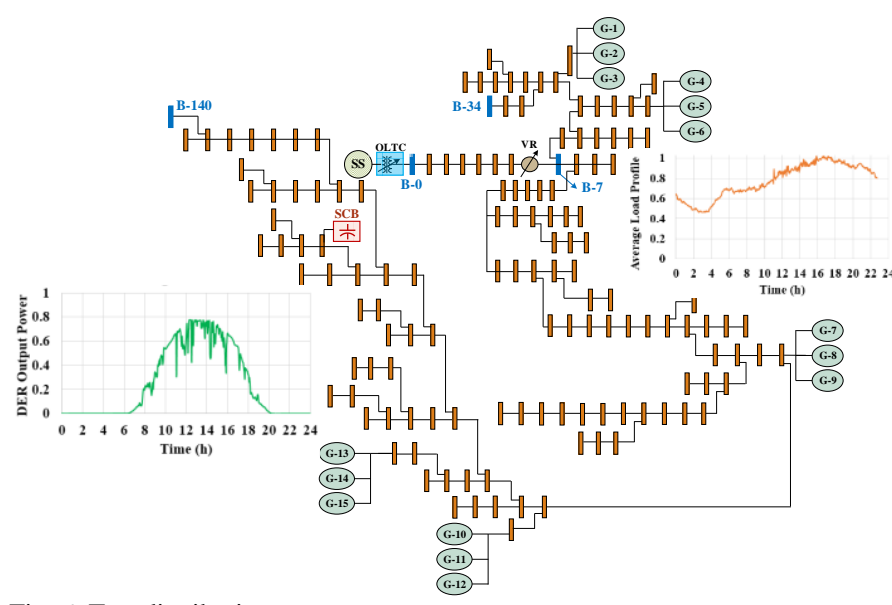

Fig. 6. Test distribution power system

$$
\left\{\begin{array}{ll}
\mathrm{k}^{+}=1 ; & \mathrm{n} \leq 0.02 \\
\mathrm{k}^{+}=\left(1>\mathrm{k}^{+}>0\right) ; & 0.02<\mathrm{n}<1 \\
\mathrm{k}^{+}=0 ; & \mathrm{n}=1
\end{array}\right\} \text { where } n=\frac{V_{p c c}^{-}}{V_{p c c}^{+}}
$$

The proposed voltage control strategy may not able to provide complete regulation of voltage unbalance at PCC in the three-wire system. However, it reduces the voltage unbalance and neutralize the active power oscillations during unbalanced voltage conditions

\section{RESULTS AND DISCUSSIONS}

A $12.47 \mathrm{kV}$ Southern California distribution power system is used to investigate the proposed voltage control strategies in both MATLAB-Simulink and conduct time-domain simulations with one-day realistic load and solar generation profile (time resolution of 60 seconds). Also, ETAP simulation software is used for power losses estimation and it verifies the Matlab/Simulink results. The voltage-dependent load model is designed for increasing the accuracy of the system. The active and reactive power consumption of the load is designed such that it varies during the changes in bus voltage over the consideration of active and reactive power coefficients. Active and reactive power coefficients are considered as 1.38 and 3.22, respectively. In case of PV model, grid connected PV array model is created with external control. The active power is externally controlled by the realtime output power data and reactive power control is designed by the proposed control algorithm.

The total length of the system is 5.306 miles and the recorded peak load is 17.53 MVA, where the average power factor of the system is 0.798 (lagging). The overall $\mathrm{R} / \mathrm{X}$ ratio of the system is calculated as 1.77 . The circuit contains 140 buses and a substation transformer equipped with an OLTC. Further, one SVR and one SCB rated at $1000 \mathrm{kVAr}$ are located at Bus-7 and Bus-121, respectively to regulate the system voltage. The SCB is operated through time-based control during the peak load period. The SVR is modelled by incorporating 33 taps in the series winding, and each tap change can vary the voltage in the amount of $0.00625 \mathrm{p}$. $\mathrm{u}$ in the system., whereas OLTC is established with 16 taps. The intended time delay is set at 30 s and it is considered during initial tap change only. The selection and transition time of each tap change is selected as $5 \mathrm{~s}$, and instantaneous reset
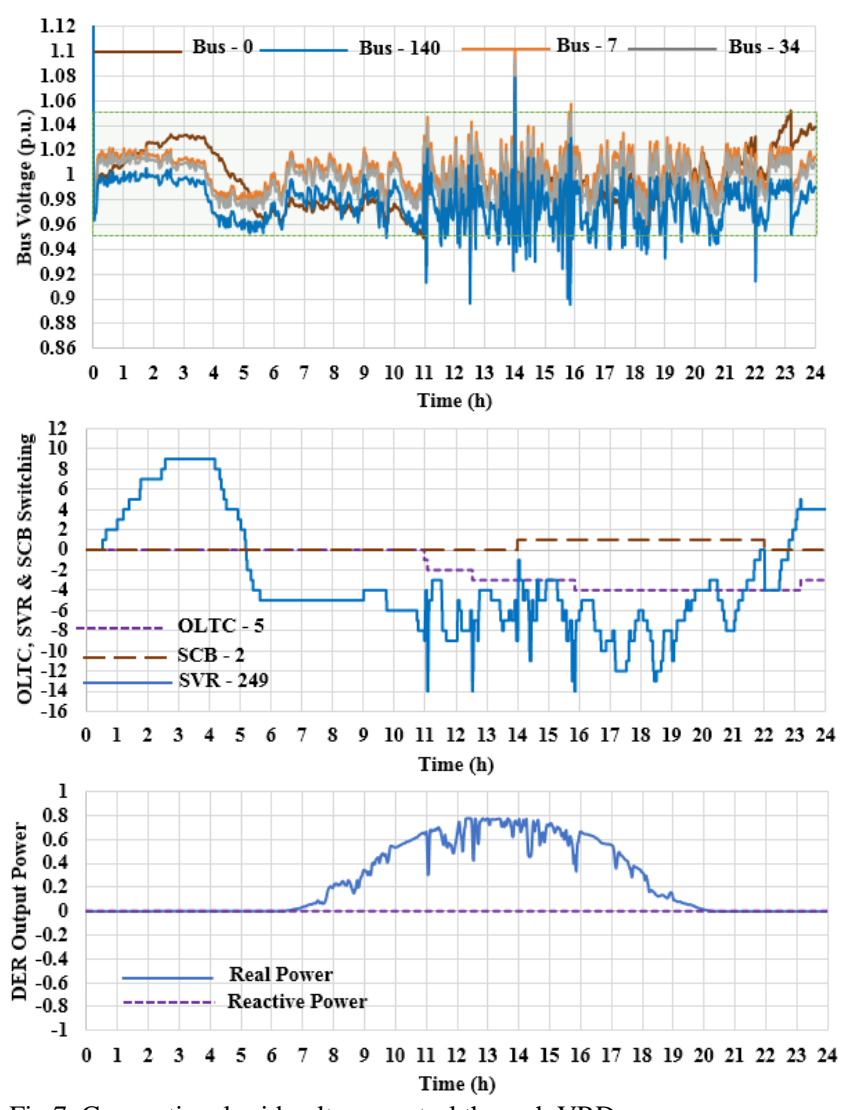

Fig.7. Conventional grid voltage control through VRDs

timer/counter logic is followed in the LTC - SVR unit. The accepted voltage bandwidth is selected for the SVR unit is between 0.98 p.u. and 1.02 p.u. However, voltage bandwidth for OLTC unit is selected at 5\% variation with the reference voltage of 1 p.u., and intentional time delay is set at 60 s. Fifteen solar units each rated at $200 \mathrm{~kW}$ is located at the different zones of the system and voltage-reactive power control mode characteristic is modelled in these units. Therefore, the capacity of DER penetration is estimated as $20.5 \%$ in the distribution system. The specified operating voltage limits for the test system are within $\pm 5 \%$ from a nominal voltage (1 p.u). The test system, load profile and solar generation profiles are presented in Fig. 6. The solar power generation profile is the same for all the units; however, power generation in all units is shifted by several seconds in consideration of moving clouds. Furthermore, time constants of synchronous generator dynamics, transient current decay, and auxiliary time constant in DER unit are considered as $1.5 \mathrm{~s}, 1 \mathrm{~s}$, and $2 \mathrm{~s}$, respectively. The entire system is simulated for a day $(24 * 60 * 60$ s) with the conventional and proposed voltage control strategies and the results are presented in Fig. 7 through Fig. 16.

\section{A. Conventional Grid Voltage Control through VRDs}

The switching of SCB is operated through time-based control and it is switched ON during peak load period, i.e. between $14 \mathrm{~h}$ and $22 \mathrm{~h}$. The initial tap position of OLTC and SVR is assumed to be at tap- 0 . The solar units generate the maximum power of 0.78 p.u. and they intermittently deliver power to the grid. In this control strategy, these solar units are not allowed to regulate the grid voltage through reactive power control (IEEE 1547:2003). The simulated results are 

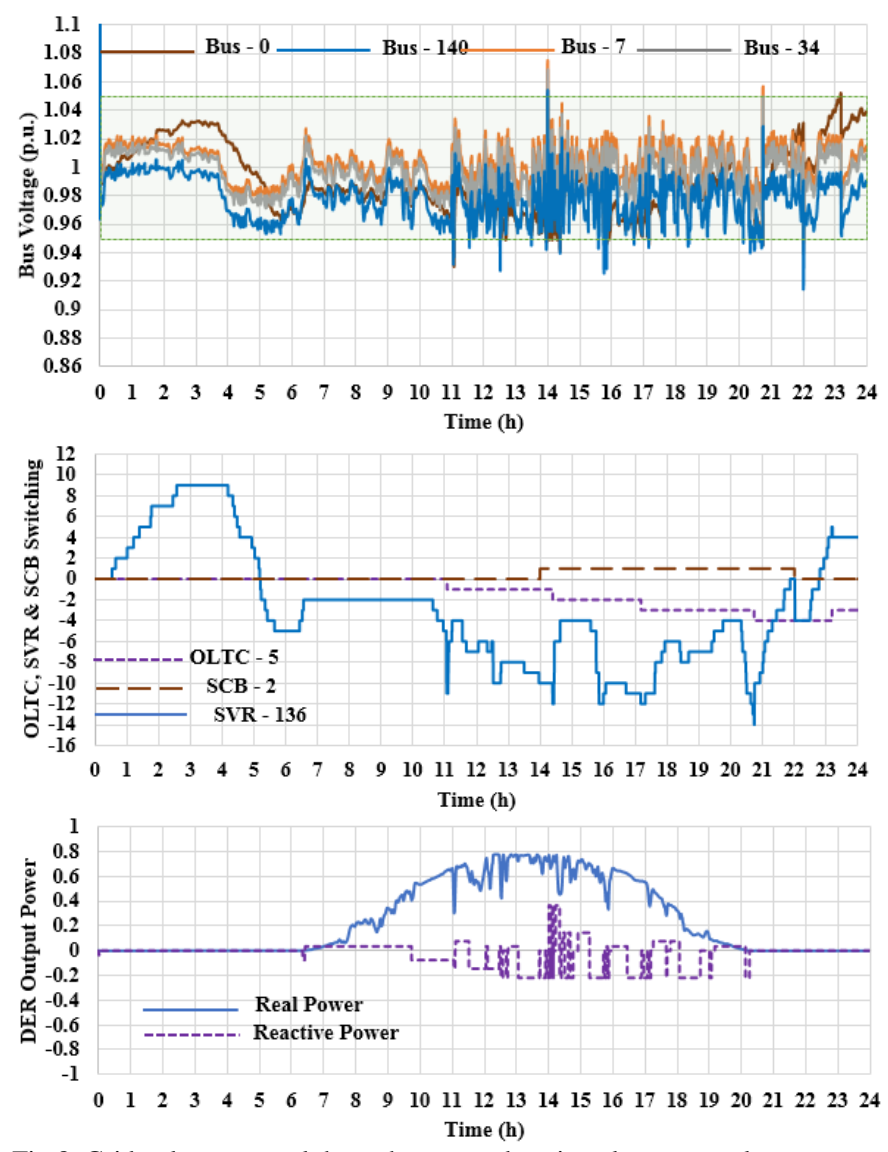

Fig.8. Grid voltage control through proposed static voltage control

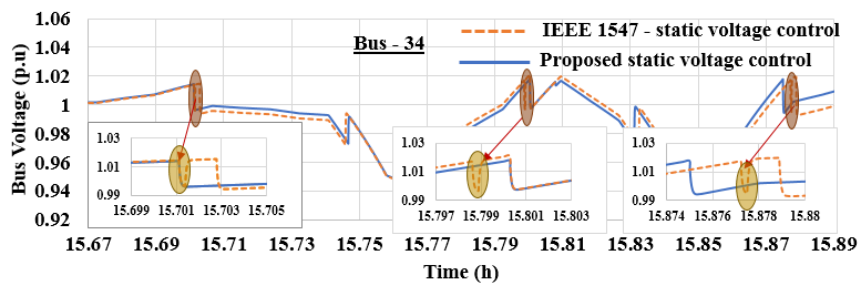

(a) bus voltage

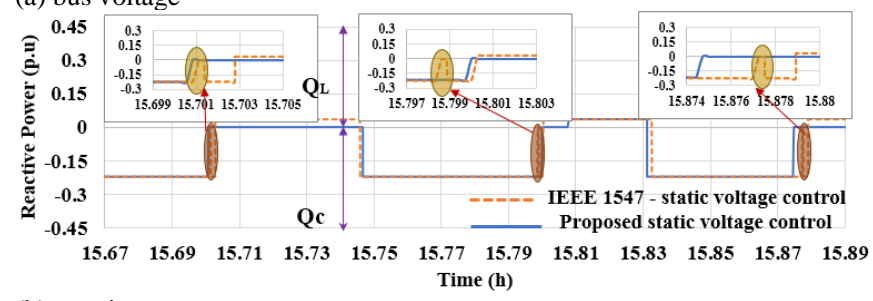

(b) reactive power

Fig.9. Comparison of static voltage control strategies

shown in Fig. 7. It is inferred that; (i) these VRDs are not operated during the momentary voltage sag; therefore, quality of the grid voltage is disturbed during this period, (ii) length of time that bus voltages are outside the accepted voltage bandwidth is high; sometimes it may heavily impact the load/generator connected in it (especially doubly fed induction machines), (iii) it increases the number of switching operations of both SVR (249 tap changes) and OLTC units (5 tap change) during sudden fluctuations in load and DERs active power generation; it increase the wear and tear of the VRD units and leads to an increase in maintenance costs.
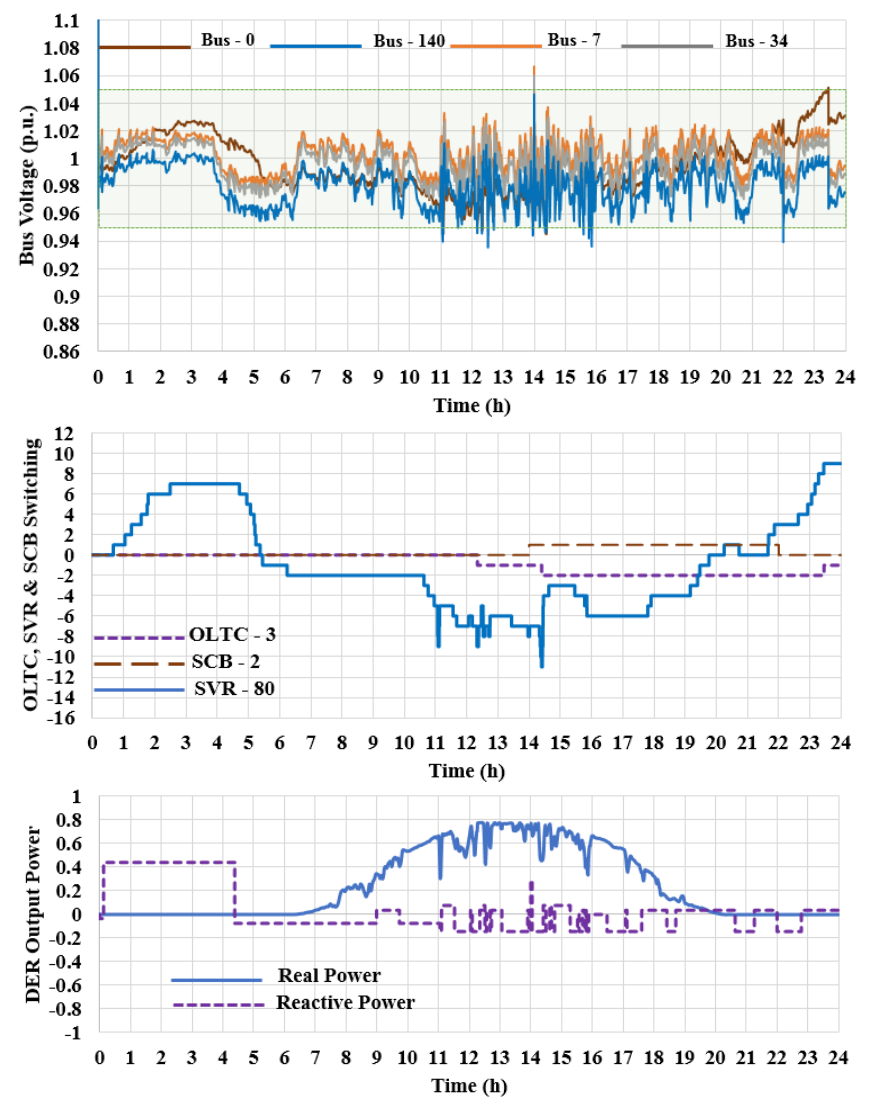

Fig.10. Grid voltage control through dynamic and extensive voltage control

\section{B. Proposed Static Grid Voltage Control}

In this control strategy the solar units follow the IEEE 1547:2018 guidelines in view of maximum support and it follows the control strategy shown in Fig. 4. The control for the VRDs are similar to the previous method. The simulated results for this proposed static voltage control strategy is shown in Fig. 8 and Fig. 9. It is inferred that this strategy reduces the number of switching operations of VRD units (i.e. SVR tap changes reduced to 136 from 249) and the time outside the accepted voltage bandwidth. It reduces the switching of solar inverter (DER) units to provide reactive power to the grid, which ultimately reduces the grid oscillatory behavior (shown in Fig. 9). However, it does not provide dynamic grid voltage support during active power variations in DER units. Further, reactive power support from DER units are limited with the capacity of $44 \%$, which may impact the voltage quality during huge load changes, active power variations and grid faulty conditions, etc.

\section{Proposed Dynamic and Extensive Voltage Control}

In this voltage control strategy, DER unit can provide dynamic and extensive voltage support to the grid. Reactive power delivery of DER unit is limited by the unit capacity and their active power generation. Therefore, it can provide maximum reactive power support during minimum power generation. In this control, extensive capacitive reactive power is supplied when the voltage goes to below 0.95 p.u., likewise, extensive inductive reactive power is supplied when the voltage goes to greater than 1.05 p.u., it increases the reactive power support. The simulated results for the proposed control strategy are shown in Fig. 10. It is inferred that DER units 


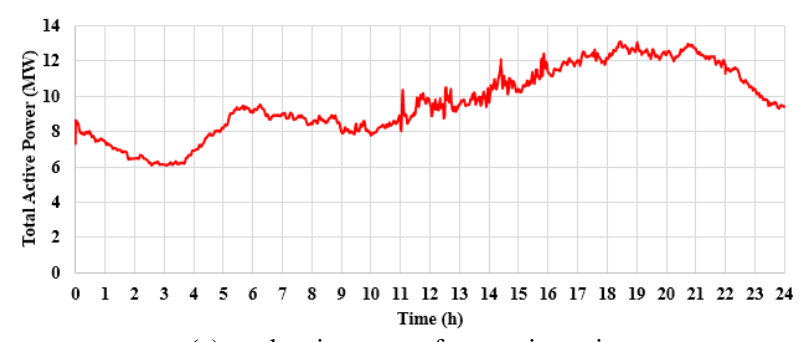

(a) total active power from main station

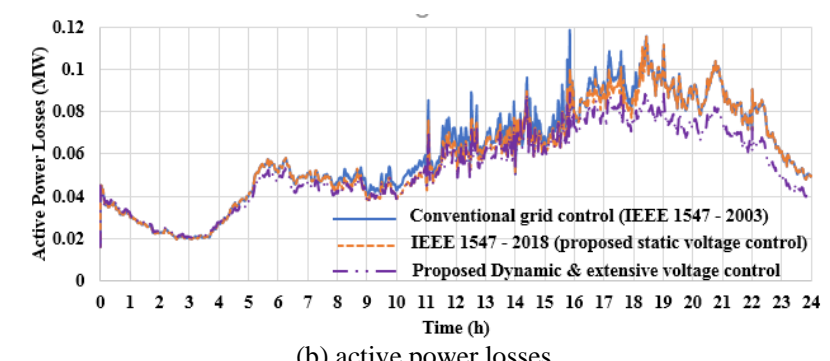

(b) active power losses

Fig.11. Comparison of active power losses of the system with respect to grid voltage control strategies

Table. 2 Comparison of active power losses in the test system

\begin{tabular}{|c|c|c|}
\hline Grid voltage control strategies & $\begin{array}{c}\text { Power } \\
\text { Losses } \\
\text { (kWh/day) }\end{array}$ & $\begin{array}{l}\text { Percentage of } \\
\text { Losses* } \\
(\%)\end{array}$ \\
\hline $\begin{array}{l}\text { Conventional grid voltage control } \\
\text { (IEEE 1547-2003) }\end{array}$ & 242.38 & 6.646 \\
\hline $\begin{array}{l}\text { IEEE } 1547-2018 \text { (proposed static } \\
\text { voltage control) }\end{array}$ & 235.409 & 6.455 \\
\hline $\begin{array}{l}\text { Proposed dynamic and extensive } \\
\text { voltage control }\end{array}$ & 213.864 & 5.864 \\
\hline
\end{tabular}

connected in bus 21 (G1-G3) supplies inductive reactive power to the grid between $0 \mathrm{~h}$ and $4 \mathrm{~h}$ (shown in Fig. 10) because of SVR and OLTC units are initially set as zero, and total load of the system during aforesaid period is minimum (about $40 \%-60 \%$ of the peak load). Nevertheless, DER units (G7 - G15) support capacitive reactive power to the grid during the periods in view of system losses and maintain the voltage in the buses. From the results, it shows that the proposed dynamic and extensive control strategy is a suitable option among the voltage control methods since, (i) it significantly reduces the switching operations of VRDs, (ii) it minimizes the percentage of time that bus voltages outside the stipulated bandwidth, (iii) it supplies instantaneous reactive power support to the grid during momentary active power variations, which increase the voltage quality in the network, and finally (iv) it reduces the grid oscillatory behavior without any remote control system. The comparison of active power losses of the test system with respect to the voltage control strategies are given in Fig.11 and Table. 2. It confirms that the proposed dynamic and extensive control method conserve the active power of about $9.15 \%$, and $11.7 \%$ compared to IEEE

(a)

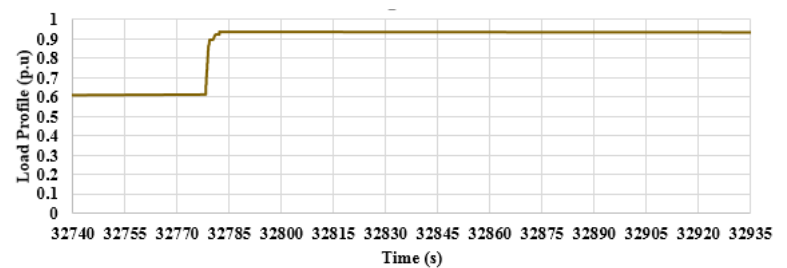

1547-2018 and conventional grid voltage control method (IEEE 1547-2003), respectively. The comparison of voltage control strategies with respect to sudden change in load and active power generation is discussed below.

\section{(i) Case 1: Sudden increase in load}

Load connected in the buses between B10 and B88 is intentionally increased as shown in Fig.12a and results are analyzed through different voltage control methods. The fault is injected at 32778s (i.e. $9.105 \mathrm{~h}$ ) and results are shown in Fig. 12b. It is inferred that during conventional voltage control bus voltage is back to the safety region through SVR and OLTC units; it takes about 104 s to reach the voltage safety region. In case of static voltage control, DER unit reacts after $2.5 \mathrm{~s}$ from the voltage variation and primarily pullback the bus voltage to 0.935 p.u. considering reactive power utilization by IEEE 1547, then it waits for SVC to operate and it takes 50s to pullback the voltage to the safety region. In case of extensive control, the available DER unit reactive power is utilized and pullback the voltage to the safety region within $4.5 \mathrm{~s}$. Furthermore, it is observed that SVR and OLTC units are not operated during this control.

\section{(ii) Case 2: Sudden reduction in load}

In this case, load connected in the buses between B10 and B43 is intentionally reduced as shown in Fig.13a and result are given in Fig. 13b. In conventional voltage control strategy, voltage is increased to 1.10 p.u. and continued about $34 \mathrm{~s}$, which is very harmful in the DER rich network. Also, bus voltage is outside the safety margin about 58s. In case of DER static voltage control method, voltage transients reach to 1.09 p.u. and voltage is continued for 10 s in the outside safety region. However, dynamic and extensive voltage control

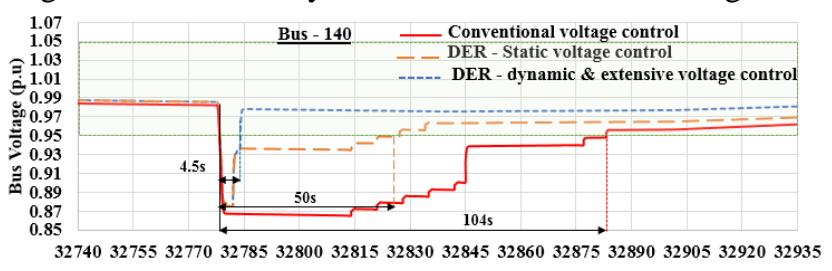
Time (s)

Fig.12. Grid voltage control methods during sudden increase in load profile (a) load profile, (b) bus voltage
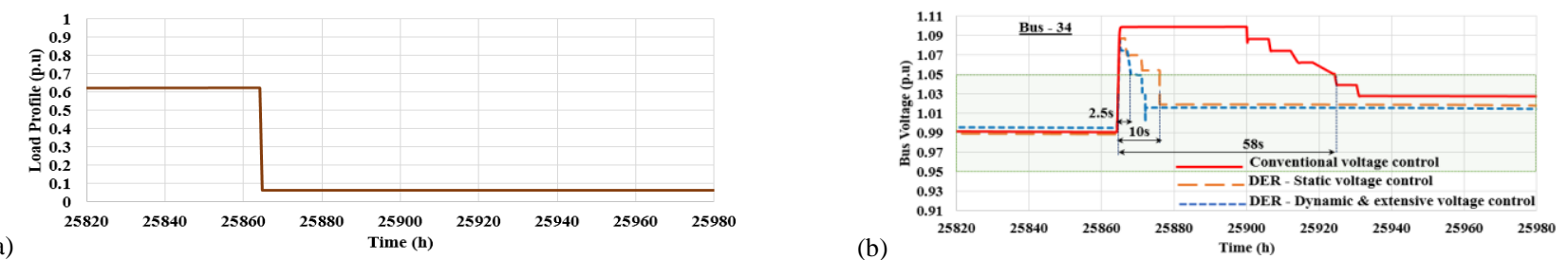

Fig.13. Grid voltage control methods during sudden drop in load profile (a) load profile, (b) bus voltage 
(a)

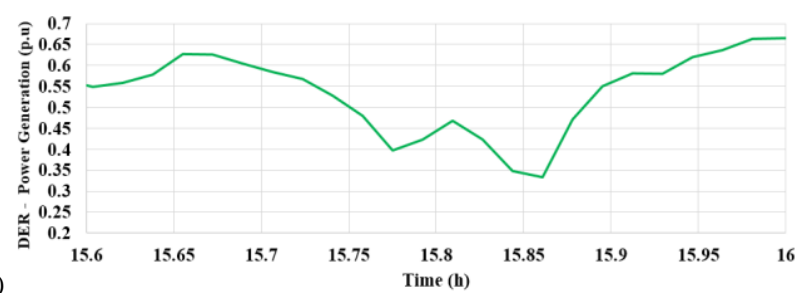

Fig.14. Grid voltage control methods during variation in DER active power (a) DER-active power, (b) Substation voltage (a)

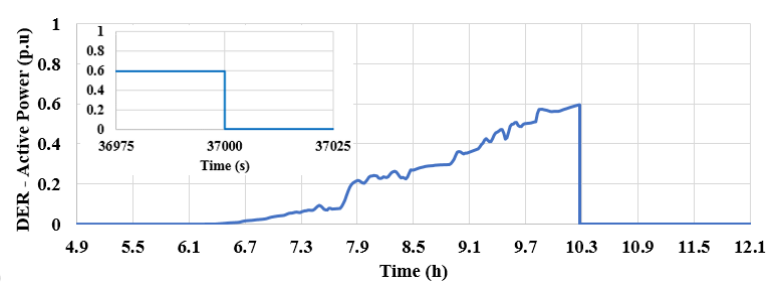

Fig.15. Grid voltage control methods during variation in DER a

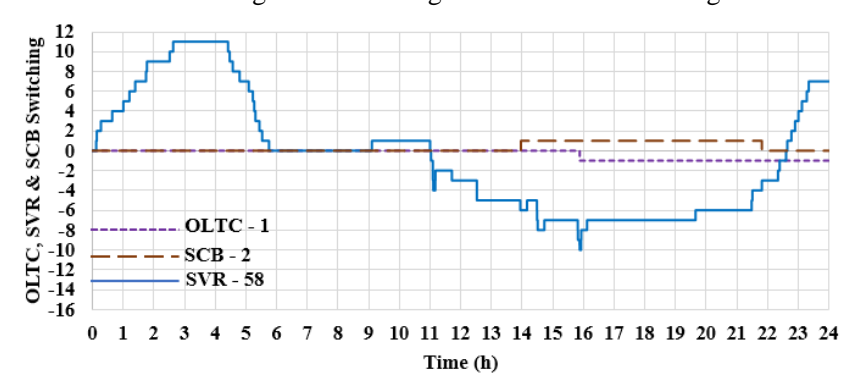

Fig. 16. VRDs switching with higher DER-penetration (41\%) in a test system

strategy reduces the voltage transients and suddenly pullback the bus voltage to the safety region within $2.5 \mathrm{~s}$. Further, it reduces the voltage outside the stipulated bandwidth in the network.

(iii) Case3: Variation in DER active power generation.

Fig. $14 \mathrm{~b}$ shows the substation voltage at different voltage control methods during variation in active power generation in DER units (shown in Fig. 14a). From the results, it is observed that during conventional voltage control the substation voltage profile is varied according to the DER active power output and goes outside the accepted voltage limit in several periods. In case of static control, substation voltage profile is improved compared to the conventional method, however, bus voltage is close to outside of the safety voltage region, also voltage variation is high. But dynamic and extensive voltage control improves the voltage profile in substation compared to other voltage control methods and maintain the voltage quality during variation in DER active power generation. Likewise, DER units (G1-G6) connected in the test system is intentionally tripped at $10.2778 \mathrm{~h}$ (37000s) and the results are given in Fig. 15. It shows that dynamic and extensive voltage control strategy suddenly pullback the bus voltage to the safety region when compared to other grid voltage control methods.

The proposed control strategy provides more reactive power support to the grid when DER penetration is higher in the power distribution. Therefore, it could ignore the use of additional capacitor banks and voltage regulators in the future system when the load is increased. However, reactive power support from the DER unit should considers V-Q relationship
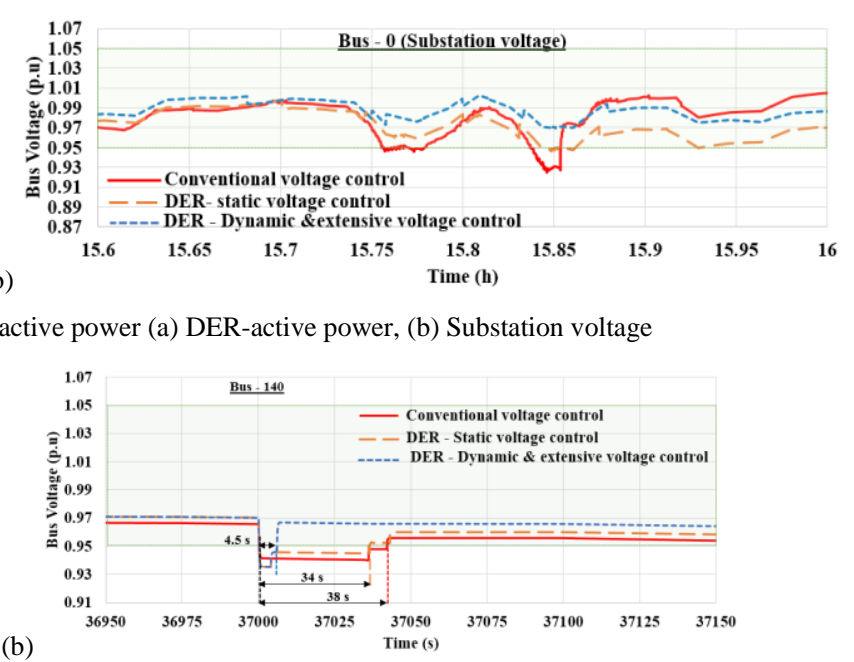

(b)

of a power distribution for maximizing the efficiency and grid stability. The proposed dynamic and extensive control is tested with $41 \%$ DER penetration power distribution and results are given in Fig. 16. It verifies that the number of switching operations of OLTC (1) and SVR (58) is reduced in comparison with less DER penetration (21\%) power distribution.

Considering above scenarios, the proposed method can provide grid voltage support to prevent the system from tripping during cyber-attack on smart meters and active power controller in DER units. In case of cyber-attack on active power in DER unit, the proposed method has a feature that provide instantaneous reactive power support considering active power variations. Therefore, during the cyberattack on active power (i.e. active power may reduce to certain value/zero) the proposed control could provide equivalent reactive power to the grid for maintaining the grid voltage. The cyber-attack on smart meter could connect or disconnect the loads in the power distribution. During the attack, the proposed dynamic and extensive voltage control take efforts to maintain the voltage at the stipulated bandwidth $(<0.95 \mathrm{p}$. $\mathrm{u}$ to $1.05 \mathrm{p}$. u) without affecting the active power generation. Fig. 12 and Fig. 13 shows the simulation results for the sudden increase and reduction in load, respectively (i.e., it is considered as cyber-attack on smart meter).

In addition, the proposed voltage control increases the voltage security of the system through maintaining the bus voltages in the specified voltage limits during the various power quality disturbances. It also improves the transient and steady state voltage stability of the system which increase the system availability.

\section{CONCLUSION}

This paper has presented two voltage control strategies in DER units for the effective voltage regulation and security in a realistic California distribution power system. The practical limitations of the voltage regulating devices are studied, and the effective time-graded control is implemented to reduce the simultaneous and negative operation of VRDs and DER units. The static voltage control strategy provides voltage support to 
the grid as per IEEE 1547:2018 regulations and it reduces the switching operations of VRDs and reduces the grid oscillatory actions. In case of dynamic and extensive voltage control strategy, it massively reduces the switching operations of VRDs and improve the voltage quality in the power distribution compared to other voltage control methods. The time-domain simulation results revealed that the reliable and security can be achieved in the distribution power system through the practice of dynamic and extensive voltage control strategy.

\section{ACKNOWLEDGMENT}

The authors gratefully acknowledge Southern California Edison for providing the circuit information and measurement data for modeling. They would also like to thank ETAP Inc., United States, for the ETAP simulation software support.

\section{REFERENCES}

[1] Renewable 2011, "Global status report -A comprehensive annual overview of the state of renewable energy, 2011.

[2] Renewable 2018, "Global status report -A comprehensive annual overview of the state of renewable energy, 2018.

[3] R. A. Walling, R. Saint, R. C. Dugan, J. Burke, and L. A. Kojovic, "Summary of distributed resources impact on power delivery systems," IEEE Trans. Power Del., vol. 23, no. 3, pp. 1636-1644, Jul. 2008.

[4] IEEE Std 1547TM-2018, IEEE Standard for Interconnection and Interoperability of Distributed Energy Resources with Associated Electric Power Systems Interfaces, 15 February 2018.

[5] T. Stetz, F. Marten, and M. Braun, "Improved low voltage gridintegration of photovoltaic systems in Germany," IEEE Trans. Sustain. Energy, vol. 4, no.2, pp. 534-542, April 2013.

[6] EPRI, "Advanced voltage control strategies for high penetration of distributed generation," EPRI Technical Report 1020155, Dec. 2010.

[7] A. Singh and P. W. Lehn, "Nonlinear reactive power control scheme to maximize penetration of distributed generation in distribution networks," IEEE Electrical Power and Energy Conf., Saskatoon, SK, 2017, pp. 1-6.

[8] E. Serban, M. Ordonez and C. Pondiche, "Voltage and frequency grid support strategies beyond standards," IEEE Trans. Power Electron., vol. 32, no. 1, pp. 298-309, Jan. 2017.

[9] M. A. Shuvra and B. H. Chowdhury, "Autonomous control of smart inverters in grid connected and islanded mode," IEEE Power \& Energy Society Innovative Smart Grid Tech. Conf., Washington, DC, 2017, pp. $1-5$.

[10] X. Zhao, L. Chang, R. Shao and K. Spence, "Power system support functions provided by smart inverters- A review," CPSS Trans. Power Electron. and Appl., vol. 3, no. 1, pp. 25-35, March 2018.

[11] J. Morren, S. W. H. de Haan, and J. A. Ferreira, "Contribution of DG units to voltage control: active and reactive power limitations," IEEE Power Tech Conf., St. Petersburg, Russia, pp. 1-7.

[12] D. Ranamuka, A. P. Agalgaonkar, and K. M. Muttaqi, "Investigating the operation of multiple voltage regulators and DG in a distribution feeder," Energy Procedia, vol. 14, pp. 1945-1950, Mar. 2012.

[13] F. A. Viawan and D. Karlsson, "Voltage and reactive power control in systems with synchronous machine-based distributed generation," IEEE Trans. Power Del., vol. 23, no. 2, pp. 1079-1087, Apr. 2008.

[14] M. Kraiczy, T. Stetz, and M. Braun, "Parallel operation of transformers with on load tap changer and photovoltaic systems with reactive power control," IEEE Trans. Smart Grid, vol. 9, no. 6, pp. 6419-6428, Nov. 2018.

[15] T.T. Ku, C.H. Lin, C.S. Chen, and C.T. Hsu, "Coordination of transformer on-load tap changer and PV smart inverters for voltage control of distribution feeders," IEEE Trans. Ind. Appl., vol. 55, no. 1, pp. 256-264, Feb. 2019.

[16] D. Ranamuka, A. P. Agalgaonkar, and K. M. Muttaqi, "Online voltage control in distribution systems with multiple voltage regulating devices," IEEE Trans. Sustain. Energy, vol. 5, no.2, pp. 617-628, April 2014.

[17] H. S. Bidgoli and T. Van Cutsem, "Combined local and centralized voltage control in active distribution networks," IEEE Trans. Power Systems, vol. 33, no. 2, pp. 1374-1384, March 2018.
[18] M. Kraiczy, M. Braun, G. Wirth, T. Stetz, J. Brantl, and S. Schmidt, "Unintended interferences of local voltage control strategies of HV/MV transformer and distributed generators," $28^{\text {th }}$ Eur. PV Solar Energy Conf. Exhibit., Paris, France, 2013, pp. 4217-4224.

[19] Slobodan N. Vukosavic, "Grid-side converters control and design: interfacing between the ac grid and renewable power sources, Springer international publishing, Switzerland, March 2018.

[20] P. Kundur, 'Power System Stability and Control', McGraw-Hill, 1994.

[21] Eaton, AUTOVAR 300 Automatically Switched Capacitor Bank, Instruction Manual IM02607003E, September 2013.

[22] T.M. Blooming, and D. J. Carnovale, "Capacitor Application Issues", IEEE Trans. Ind. Appl., Vol. 44, No. 4, pp. 1013- 1026, July/August 2008.

[23] Waukesha, Load tap changer, UZD Technical Manual, 2016.

[24] ABB, On load tap changers, type UC-Technical guide, Nov 2016.

[25] ANSI C84.1-2016, American national standard for electric power systems and equipment- voltage ratings (60 Hertz), June 2016.

[26] D. Wareham, Technical presentation on step voltage regulators, cooper power systems, Eaton, 2013.

[27] D. F. Teshome, W. Xu, P. Bagheri, A. B. Nassif and Y. Zhou, "A reactive power control scheme for der-caused voltage rise mitigation in secondary systems," IEEE Trans. Sustainable Energy, Vol. 10, No. 4, pp. 1684-1695. October 2019.

[28] N. Jenkins, R. Allan, P. Crossley, D. Kirschen and G. Strbac, Embedded Generation, IEE Power and Energy Series 31, 2000.

[29] F. Nejabatkhah, Y. W. Li and B. Wu, "Control Strategies of Three-Phase Distributed Generation Inverters for Grid Unbalanced Voltage Compensation," IEEE Trans. Power Electron., vol. 31, no. 7, pp. 52285241, July 2016.

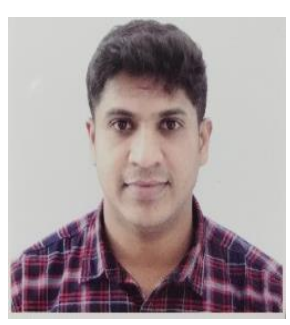

Anto Joseph received the bachelor's degree in electrical and electronics Engineering from Anna University, India, in 2008, the M. Tech degree in Power Electronics and Drives from Bharath University, Chennai, India, in 2011 and the Ph.D. degree from Hydropower Simulation Laboratory, Indian Institute of Technology Roorkee, India in July 2018.

From 2011 to 2014, he was with the St. Joseph University in Tanzania, Tanzania as a Lecturer. From August 2018 to November 2018, he was working as a Research Associate in Power Electronics Laboratory, Ajou University, Suwon, South Korea. He is currently working as a Post-Doctoral Researcher in Power Electronics Laboratory, University of California Irvine, California, USA. His current research interests include voltage control and security in power distribution system, fault diagnosis \& fault tolerant operation of electrical drives, and boost power electronic converter topologies.

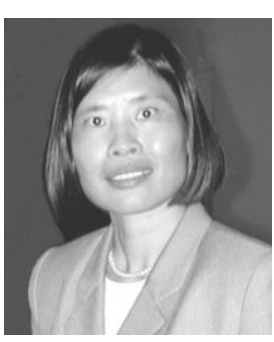

Keyue Ma Smedley (S'87-M'90-SM'97-F'08) Keyue Smedley received her B.S. and M.S. degrees in electrical engineering from Zhejiang University, Hangzhou, China, in 1982 and 1985, respectively, and the M.S. and Ph.D. degrees in electrical engineering from the California Institute of Technology, Pasadena, CA, in 1987 and 1991, respectively.

She is currently a professor in the Department of Electrical Engineering and Computer Science at the University of California at Irvine, the Director of the UCI Power Electronics Laboratory, and a cofounder of One-Cycle Control, Inc. Dr. Smedley's research interest includes high-efficiency dc-dc converters, high-fidelity class-D power amplifiers, four-quadrant three-phase and single-phase converters (covering PFC rectifiers, active power filters, inverters, VAR generation), switching capacitor converters, and utility-scale fault current limiters. Her technology has been integrated into commercial products spanning from audio amplifiers to V/VAR control, power grid dynamic voltage control, power quality control, renewable generation, energy storage system, mobile power, microgrid, etc. Her soft switching and regenerative clamping circuits are widely used in industry. Her current research activities include power grid modeling for high penetration renewables, solar power integration, power quality control, etc.

Dr. Smedley's work has resulted in more than 200 technical publications, more than ten US/international patents, two start-up companies, and numerous commercial applications. Dr. Smedley is a recipient of UCI 
Innovation Award 2005. She was selected as an IEEE Fellow in 2008 for her contributions in high- performance switching power conversion. Her work with One-Cycle Control, Inc., won Department of the Army Achievement Award in the Pentagon in 2010.

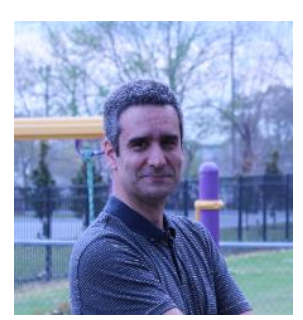

Shahab Mehraeen (S'08-M'10) received the B.S. degree in electrical engineering from Iran University of Science and Technology, Tehran, Iran, in 1995, the M.S. degree in electrical engineering from Esfahan University of Technology, Esfahan, Iran, in 2001, and the Ph.D. degree in electrical engineering from Missouri University of Science and Technology, Rolla, in 2009.

Prior to his $\mathrm{PhD}$, he worked for power generation industry for four years in power plant retrofit projects and control systems. He joined the Louisiana State University, Baton Rouge, LA, USA, in 2010. His current research interests include micro grids, renewable energies, power systems dynamics, protection, and smart grids. In addition, he conducts research on decentralized, adaptive, and optimal control of dynamical systems. Shahab Mehraeen is a National Science Foundation CAREER awardee and holds a U.S. patent on energy harvesting and a few more pending. 